Author's post print: Carlos .J. Slebi-Acevedo Pedro. Lastra-González, Irunne. Indacoechea-Vega, Daniel. Castro-Fresno, Laboratory assessment of porous asphalt mixtures reinforced with synthetic fibers, Constr. Build. Mater. 234 (2020). doi:10.1016/j.conbuildmat.2019.117224.

\title{
Laboratory assessment of porous asphalt mixtures reinforced with synthetic fibers
}

Carlos .J. Slebi-Acevedoa, Pedro. Lastra-Gonzáleza, Irunne. Indacoechea-Vegaa , Daniel. Castro-Fresnoa*

a GITECO Research Group, Universidad de Cantabria, Avda. de Los Castros s/n, 39005 Santander, Spain.

* Correspondence: castrod@unican.es

\section{Abstract}

Porous asphalt (PA) mixtures have become a new alternative in the development of new road pavement surface layers given their multiple advantages such as surface runoff improvement, the decrease of the urban heat island effect, the reduction of road traffic noise and the minimization of the spray and aquaplaning effect leading to a safer driving. However, the durability of these mixtures is not as good as for dense graded mixtures. This research studies the effectiveness of adding a blend of polyolefin/aramid fibers and homopolymer polyacrylonitrile fibers in PA mixtures in terms of functionality and mechanical performance. Furthermore, changes in the filler content were assessed. The experimental testing plan includes air voids characterization, permeability, moisture sensitivity and particle loss in dry and wet conditions. Improvements on the mechanical performance can be observed in dry conditions. Finally, the fracture energy, postcracking energy and toughness were also analyzed. The results show that the addition of fibers brings ductility to the PA mixture improving toughness while maintaining functionality since the air void content remains over $20 \%$.

\section{Highlights}

- PA mixtures with $0.05 \%$ of synthetic fibers were assessed.

- The influence of filler content on the fiber modified asphalt mixture performance was considered.

- The addition of synthetic fibers did not produce significant effects on the air voids.

- Fibers addition improves the PA mechanical properties in dry conditions.

\section{Key words}

Polyolefin, aramid, polyacrylonitrile, fibers, porous asphalt, water sensitivity, toughness.

\section{Introduction.}

Porous asphalt (PA) mixtures have become an alternative to conventional dense asphalt mixtures due to their several advantages such as their mitigation effect on storm water runoff, the improvement on the drivability in wet weather conditions and their road traffic noise reduction ability [1,2]. Other researchers recommend these mixtures due to their potential to enhance surface frictional resistance, minimize aquaplaning, improve visibility in night conditions and decrease splash and spray $[3,4]$. Moreover, thanks to its high voids content, these mixtures allow the flowing of water through the pores preventing its accumulation on the road surface [5]. Additionally, due to their higher porosity, PA mixtures exhibit a rough surface texture which increases the friction between the tire and the asphalt surface, thus contributing to reduce road accidents [6].

These mixtures have been used since 1950 to improve the frictional resistance of asphalt pavements [7]. In this sense, porous friction courses (PFC) are commonly used as non - structural 
Author's post print: Carlos .J. Slebi-Acevedo Pedro. Lastra-González, Irunne. Indacoechea-Vega, Daniel. Castro-Fresno, Laboratory assessment of porous asphalt mixtures reinforced with synthetic fibers, Constr. Build. Mater. 234 (2020). doi:10.1016/j.conbuildmat.2019.117224.

wearing courses in the United States and Europe [8]. Nonetheless, in the United States the experience on this type of mixture has been contradictory, with some states reporting good performance, while others limiting their use due to poor performance [9]. On the other hand, Massahi et al. [10] reported that raveling can be considered a substantial pavement distress that affects the security of road users and increases the need of more frequent road maintenance. In addition, given the mineral skeleton presented by the PA mixtures and the high content of voids (i.e. 20\%), these mixtures show greater problems of durability [11]. In this sense, high percentages of air voids cause the bituminous binder to be more exposed to the impact of weather, increasing the aging of the bitumen and producing a detriment effect on its cohesive and adhesive capacity [12-15]. The need to improve the mechanical performance and increase the service life of PA mixes has brought to the development of a new generation of PA mixes that incorporate polymers and other additives such as fibers $[16,17]$.

To date, the effect of different types and sizes of fibers on the mechanical performance has been investigated specially in asphalt concrete (AC). Thus, Lee et al. [18] reported an increase of about $85 \%$ in the fracture energy properties of an AC by adding $1.0 \%$ by volume of $12 \mathrm{~mm}$ long nylon fibers to the mixture. On the other hand, Kaloush et al. [19] reported that the use of a blend of polypropylene and aramid fibers in an asphalt concrete improved the performance of the mixture specially in permanent deformation, fatigue cracking and thermal cracking. Finally, Xu et al. [20] conducted laboratory tests on a fiber reinforced asphalt concrete (FRAC). The strength, strain and fatigue behavior of the FRAC were measured. Results showed an improvement in the flexural strength and the ultimate flexural strain due to the addition of polymer fibers (polyester and polyacrylonitrile). Rutting resistance, fatigue life and indirect tensile strength (ITS) were also improved with the incorporation of the polymer fibers due to their networking function. A polyester fiber content of $0.35 \%$ by mass of mixture was suggested to achieve the best performance in terms of permanent deformation and ITS.

Less research has been carried out on the modification of porous asphalt mixtures with fibers. Chowdhury et al [21] studied the effect of tire fibers in PA mixtures. Drain-down, dynamic modulus, indirect tensile strength and Hamburg wheel tracking test were applied reporting that tire fibers could be an alternative to cellulose fibers. In another research, Xiang Ma et al. [22] employed various additives in a porous asphalt mixture concluding that polyester fibers should be used in a PA mixture because significant improvements on the durability and low cracking resistance were found. Andrés-Valeri et al. [16] assessed the durability of using Tetra brick aseptic (TBA) fibers in PA mixtures as an environmentally friendly additive. The authors reported an increment in the indirect tensile strength (ITS) in the range of $22 \%$ when the fiber is added compared to the reference mixtures. In a much wider study, Punith and Veeraragavan [3] incorporated reclaimed polyethylene (PE) fibers in open graded friction course (OGFC) mixtures. Several laboratory tests were carried out on these mixtures to determine tensile strength, moisture sensitivity and fatigue damage. Results indicated that the incorporation of PE fibers in the mixture improved the three properties in comparison to the control mixtures without fibers. Finally, Lopes et al. [2] evaluated the performance of PA mixtures with cellulose fibers, being these fibers one of the most common additives in hot mix asphalts (HMA) [15,23-25]. In this research, the Indirect Tensile Stiffness Modulus (ITSM), water sensitivity, permeability and permanent deformation tests were carried out. The authors concluded that the absorption of the bitumen by the cellulose fibers improved the water drainage through the pores and therefore the PA mixture permeability. In addition, a reduction in the particle loss of around $11 \%$ was observed with the addition of this type of fibers.

While published studies have demonstrated positive results when aramid and polyacrylonitrile fibers are added to dense asphalt mixtures, the incorporation of this type of reinforcement in PA mixtures has not been investigated in depth. Thus, the main aim of this paper is to evaluate 
Author's post print: Carlos .J. Slebi-Acevedo Pedro. Lastra-González, Irunne. Indacoechea-Vega, Daniel. Castro-Fresno, Laboratory assessment of porous asphalt mixtures reinforced with synthetic fibers, Constr. Build. Mater. 234 (2020). doi:10.1016/j.conbuildmat.2019.117224.

the mechanical performance of PA mixtures that include in their composition a blend of polyolefin/aramid fibers or polyacrylonitrile fibers and compare it with the performance of a reference PA mixture without fibers. To assess this mechanical performance, the porous asphalt mixtures were designed according to European standard methods and the following experimental laboratory plan test was performed: bulk density, total and interconnected air voids, permeability test, Cantabro particle loss test in dry and wet conditions, indirect tensile strength (moisture sensitivity) and fracture energy.

\section{Materials}

\subsection{Aggregates}

Previous laboratory tests were carried out to determine the properties of the natural aggregate. Coarse ophite aggregate and fine limestone aggregate were used in this study to produce the PA mixtures. The physical properties and the limits of the Spanish Standard specifications for the highest traffic level are shown in Table 1. In this research, the grading curve employed was a PA16 in accordance with the specifications given in the Spanish guidelines [26] as shown in Fig.1.

Table 1. Properties of coarse ophite and fine limestone aggregate.

\begin{tabular}{llll} 
Characteristic & Value & Standard & Specification \\
\hline Coarse Aggregate & & & \\
\hline Specific Weight $\left(\mathrm{g} / \mathrm{cm}^{3}\right)$ & 2.794 & EN $1097-6$ & - \\
Water absortion $(\%)$ & 0.60 & EN $1097-6$ & $<1 \%$ \\
L.A abrasion $(\%)$ & 15 & EN $1097-2$ & $\leq 15 \%$ \\
Slab Index (\%) & $<1 \%$ & EN 933 - 3 & $\leq 20 \%$ \\
Polishing Value & 60 & EN 1097 - 8 & $\geq 56$ \\
& & & \\
Fine Aggregate & & & - \\
\hline Specific Weight $\left(\mathrm{g} / \mathrm{cm}^{3}\right)$ & 2.724 & EN 1097 - 6 & $>55$ \\
Sand Equivalent & 78 & EN 933-8 & \\
\hline
\end{tabular}

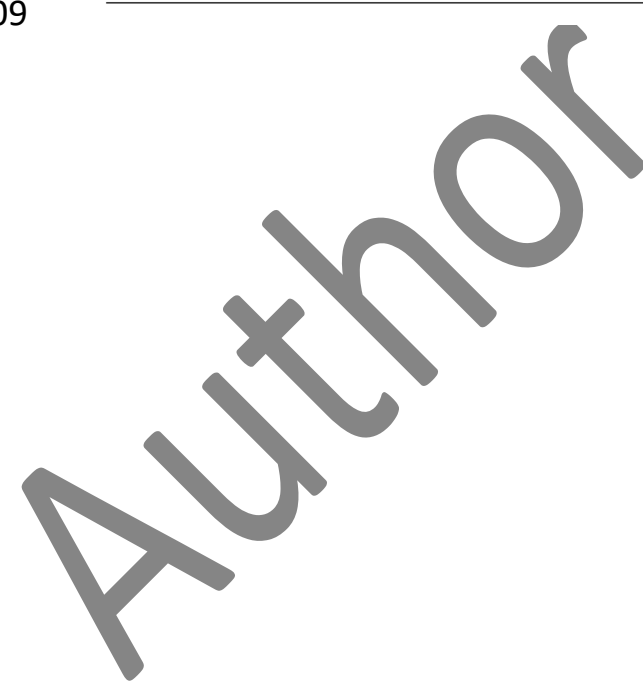


Author's post print: Carlos .J. Slebi-Acevedo Pedro. Lastra-González, Irunne. Indacoechea-Vega, Daniel. Castro-Fresno, Laboratory assessment of porous asphalt mixtures reinforced with synthetic fibers, Constr. Build. Mater. 234 (2020). doi:10.1016/j.conbuildmat.2019.117224.

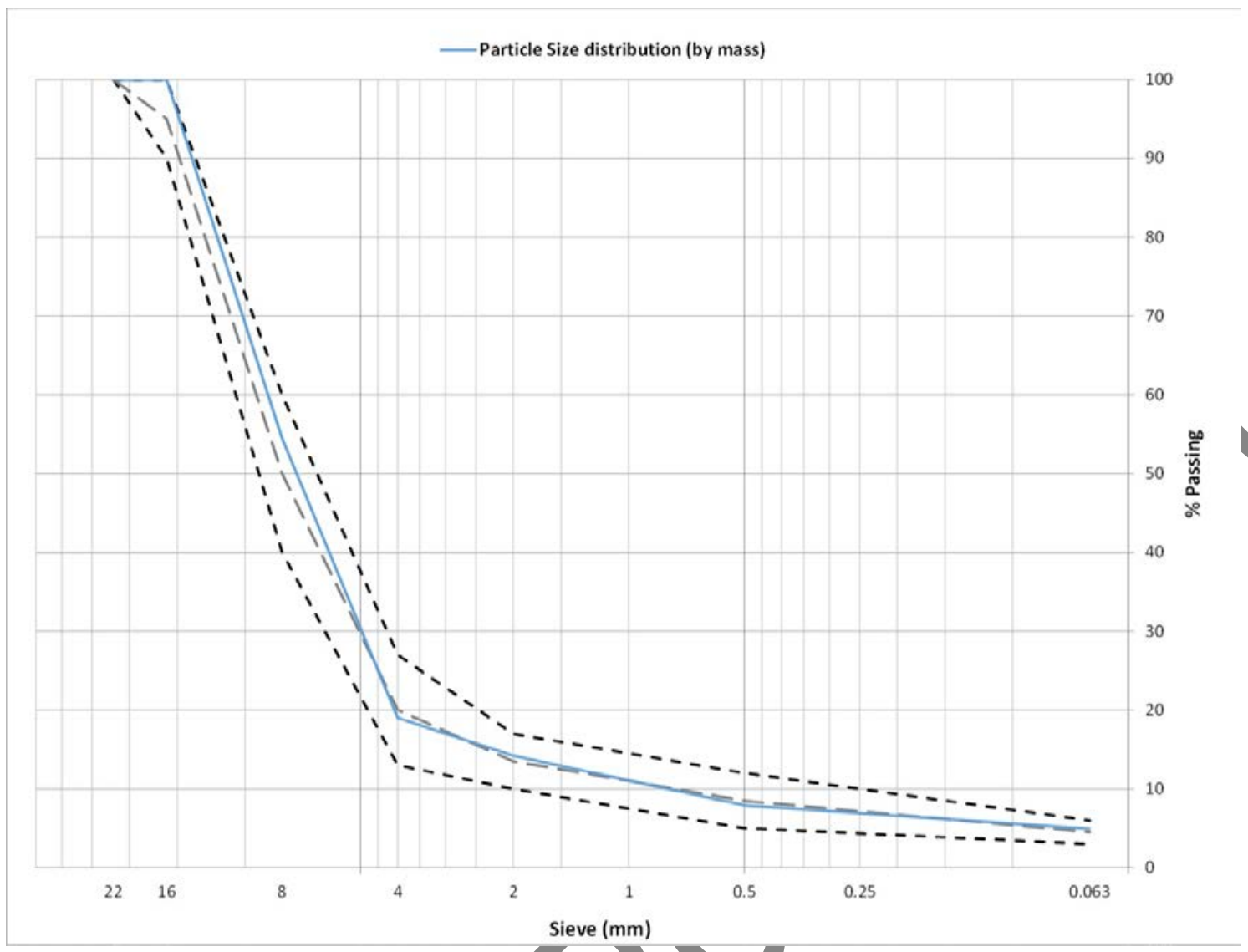

Fig.1. Particle size distribution PA mixture.

\subsection{Bituminous binder}

A conventional 50/70 penetration grade bituminous binder was employed in this research. Although usually a polymer modified asphalt is used in PA mixtures, in this research the reinforcement effect of the fibers in the PA mixture is studied with a conventional binder. The physical properties of the asphalt binder are presented in Table 2.

Table 2. Characteristics of a 50/70 penetration grade binder.

\begin{tabular}{lll} 
Characteristic & Standard & Value \\
\hline Specific weight $\left(\mathrm{g} / \mathrm{cm}^{3}\right)$ & EN 15326 & 1.035 \\
Penetration at $25^{\circ} \mathrm{C}$ & EN 1426 & 57 \\
Softening point $\left({ }^{\circ} \mathrm{C}\right)$ & EN 1427 & 51.6 \\
Fraass brittle point $\left({ }^{\circ} \mathrm{C}\right)$ & EN 12593 & -13 \\
\hline
\end{tabular}

\subsection{Fibers}

122 Two different fiber types were studied by the authors (see Fig.2). The first one consisted of a blend of synthetic fibers (aramid plus polyolefin) that has given good results in dense graded asphalt mixtures $[19,27]$. The density of this blend according to the standard method UNE-EN 1097-6 was $0.947 \mathrm{~g} / \mathrm{cm}^{3}$. The physical properties of the polyolefin/aramid fibers (PO/A) according to the manufacturers are given in Table 3. The second fiber used in this study is a homopolymer polyacrylonitrile (PAN) synthetic fiber. For this type of fiber, two different sizes, $4 \mathrm{~mm}$ and $12 \mathrm{~mm}$, were considered. For both types of fibers, the fiber content was fixed in $0.05 \%$ $\mathrm{w} / \mathrm{w}$ according to the suppliers. The physical properties provided by the manufacturers are presented in Table 4. 
Author's post print: Carlos .J. Slebi-Acevedo Pedro. Lastra-González, Irunne. Indacoechea-Vega, Daniel. Castro-Fresno, Laboratory assessment of porous asphalt mixtures reinforced with synthetic fibers, Constr. Build. Mater. 234 (2020). doi:10.1016/j.conbuildmat.2019.117224.

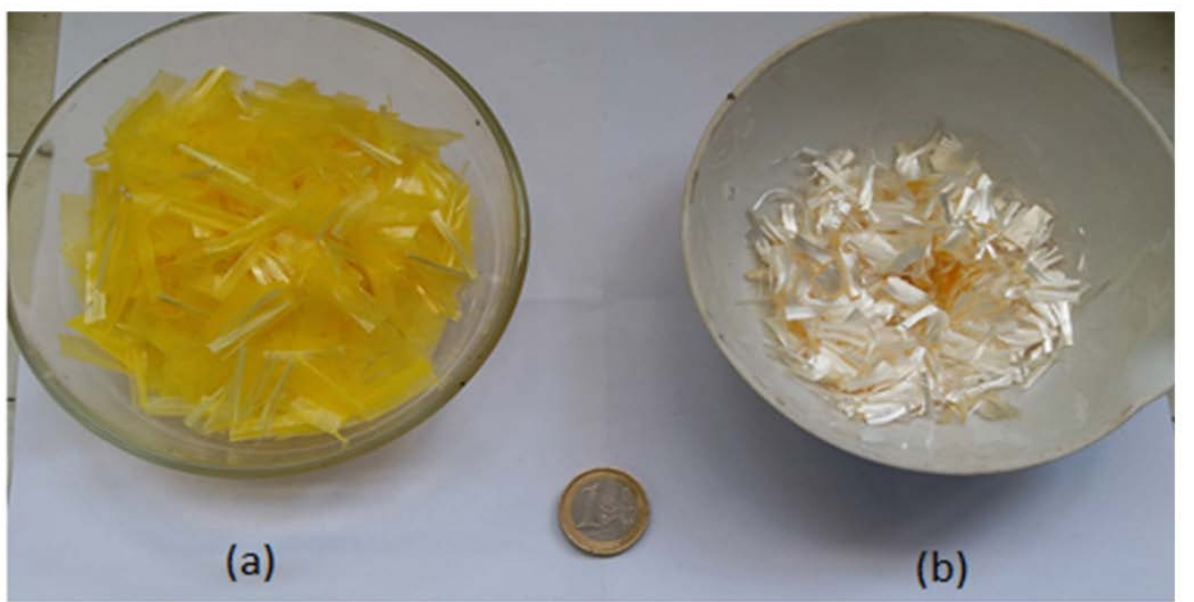

Fig.2. Types of synthetic fibers used in this work: (a) PO/A fibers and (b) PAN fibers.

Table 3. Characteristics and properties of PO/A fibers.

\begin{tabular}{lc} 
Fiber & Aramid \\
\hline Form & Monofilament \\
Color & Yellow \\
Density $\left(\mathrm{g} / \mathrm{cm}^{3}\right)$ & 1.44 \\
Length $(\mathrm{mm})$ & 19 \\
Tensile Strength (MPa) & 2758 \\
Decomposition temperature $\left({ }^{\circ} \mathrm{C}\right)$ & 157 \\
Acid/Alkali Resistance & Inert \\
\hline \multicolumn{2}{|c}{ Table 4. Characteristics and properties of PAN fibers. } \\
Fiber & Polyacrylonitrile \\
\hline Form & Staple fibers \\
Color & Bright straw yellow gold \\
Density (g/cm3) & 1.18 \\
Length (mm) & $4-12$ \\
Tenacity (MPa) & $>708$ \\
Elastic modulus (MPa) & 16500 \\
Elongation at break (\%) & $<13$ \\
Diameter (mm) & 0.0127 \\
\hline
\end{tabular}

\section{Experimental Program}

\subsection{Mix design and specimen preparation}

140 In this work, PA mixes incorporating polyolefin/aramid (PO/A) or PAN fibers were designed.

141 Eight different experimental designs were produced by varying the type of fiber (No fiber, PO/A, PAN 4 and PAN 12 ) and the amount of filler ( $4.9 \%$ and $4.3 \%$ by weight of the aggregate fraction). In all the samples, the amount of bitumen was $4.3 \%$ by weight of mixture. The nomenclature of the different designs was defined based on the type of fiber in the mixture, the length of the fiber $(\mathrm{mm})$ and the filler content in the mixture. Thus, the designed mixture PAN $12-\mathrm{A}$ corresponds to the PA mixture with PAN $12 \mathrm{~mm}$ long fibers and a filler content of $4.9 \%$. Similarly, the mixtures used as references were named RA and RB depending on the filler content. Table 5 details the different designs carried out.

Table 5. Porous asphalt mixtures designs. 
Author's post print: Carlos .J. Slebi-Acevedo Pedro. Lastra-González, Irunne. Indacoechea-Vega, Daniel. Castro-Fresno, Laboratory assessment of porous asphalt mixtures reinforced with synthetic fibers, Constr. Build. Mater. 234 (2020). doi:10.1016/j.conbuildmat.2019.117224.

150

151

152

153

154

155

156

157

158

159

160

161

162

163

164

165

166

167

\begin{tabular}{llllllll} 
ID. N & $\begin{array}{l}\text { Mixture } \\
\text { Design }\end{array}$ & \multicolumn{2}{l}{ Bitumen } & Fibers & Filler \\
\cline { 3 - 8 } & & Type & Dosage (\% b/w of mix) & Type & Length & Dosage (\%b/w of mix) & Dosage (\%b/w of aggregate) \\
\hline 1 & RA & $50 / 70$ & 4.3 & - & - & - & 4.9 \\
2 & PO/A 19 - A & $50 / 70$ & 4.3 & PO/A & 19 & 0.05 & 4.9 \\
3 & PAN 12 - A & $50 / 70$ & 4.3 & PAN & 12 & 0.05 & 4.9 \\
4 & PAN 4 - A & $50 / 70$ & 4.3 & PAN & 4 & 0.05 & 4.9 \\
5 & RB & $50 / 71$ & 4.3 & - & - & - & 4.3 \\
6 & PO/A 19 - B & $50 / 70$ & 4.3 & PO/A & 19 & 0.05 & 4.3 \\
7 & PAN 12 - B & $50 / 70$ & 4.3 & PAN & 12 & 0.05 & 4.3 \\
8 & PAN 4 - B & $50 / 70$ & 4.3 & PAN 4 & 0.05 & 4.3 \\
\hline
\end{tabular}

All the PA mixtures presented in this paper were designed according to the European Standards for Bituminous mixtures (EN 13108-7) and the Spanish specification "General Technical Requirements for Works of Roads and Bridges" [26], document approved by the Ministry of Public Works of the Government of Spain.

The asphalt samples were prepared as follows. Coarse and fine aggregates were heated in an oven at $170^{\circ} \mathrm{C}$ for six hours and then thoroughly mixed with the fibers for 20 s. Afterwards, the asphalt binder was added at $150^{\circ} \mathrm{C}$ into the mixture and continuously blended to achieve that the combination fiber-aggregate was well coated by the bitumen. It is worth mentioning that in the case of PO/A fibers, the polyolefin was added together with the asphalt binder. Finally, PA mixtures were compacted with 50 blows per side according to EN $12697-30$.

\subsection{Experimental tested plan}

An assessment of the mixture volumetric properties, durability, functionality and stability were performed in this research as shown in Table 6. Mixture volumetric properties were focused on the macroscopic evaluation [17] including bulk specific gravity of the compacted mixture, total air voids (AV), and interconnected air voids (IAV). Closed air voids were also calculated like the difference between AV and IAV [16].

Table 6. Experimental work plan.

\begin{tabular}{llll} 
Parameter & Standard method & Comments & Test Replicate \\
\hline Bulk density & EN 12697-6 & & 14 \\
Total Air voids (AV) & EN 12697-8 & & 14 \\
Interconnected Air voids (IAV) & ASTM D7063-05 & falling head from 30 to $10 \mathrm{~cm}$ & 4 \\
Vertical Permeability & Falling head permeameter & Dry condition & 4 \\
Particle loss & EN 12697-17 & Wet condition & 4 \\
Particle loss & NLT 362/92 & Dry and wet conditions & 3 \\
Indirect Tensile Strength (ITS) & EN 12697-23 & Dry and wet conditions & 3 \\
FE, PE, Toughness & - & - & 3 \\
Moisture Sensitivity & EN 12697-12 & & \\
\hline
\end{tabular}

169 Regarding the mixture mechanical performance, the Cantabro loss particle test was carried out 170 to assess the raveling of the porous asphalt mixtures [28-32]. This test measures the percentage 171 of particle loss that occurs when the specimen is subjected to abrasion in the Los Angeles 172 machine. The Cantabro test was also performed in wet conditions according to the NLT 362/92 173 Spanish standard. In this case, the specimens were submerged in water at $60^{\circ} \mathrm{C}$ for 24 hours. 174 Then the samples were kept at $25^{\circ} \mathrm{C}$ for another 24 hours before performing the test. In both 175 cases, the loss in mass is expressed as the percentage after 300 turns and is calculated according 176 to Eq.1.

$$
\text { Particle loss }(\%)=\frac{m_{i}-m_{f}}{m_{i}} * 100
$$


Author's post print: Carlos .J. Slebi-Acevedo Pedro. Lastra-González, Irunne. Indacoechea-Vega, Daniel. Castro-Fresno, Laboratory assessment of porous asphalt mixtures reinforced with synthetic fibers, Constr. Build. Mater. 234 (2020). doi:10.1016/j.conbuildmat.2019.117224.

Where $m_{i}$ and $m_{f}$ correspond to the initial and final mass of the specimens.

Concerning the indirect tensile strength (ITS) test, specimens were tested both in dry and wet conditions (ITS $S_{d r y}$ and ITS $\left.S_{\text {wet }}\right)$. The ITS was measured by loading diametrically the samples across the circular cross section and recording the load to failure. From this test, toughness can also be determined by analysing the area under the stress-strain curve as shown in Fig.3. The toughness consists of two parameters, the Fracture Energy (FE) and the Post-cracking Energy $(P E)$. The former corresponds to the area under the stress-strain curve until the strain at the maximum stress is reached, $\varepsilon_{p}$ [33]. The PE is calculated as the area under the stress-strain curve from $\varepsilon_{p}$ to $2 \varepsilon_{p}$ as suggested in [33]. According to said authors, ITS and FE have proven to be good indicators of the cracking resistance prior to major crack development and PE gives an idea of the mixture ductility and its resistance to crack propagation. In this study, the toughness, $\mathrm{FE}$ and PE were determined for all the specimens, dry and wet conditioned.

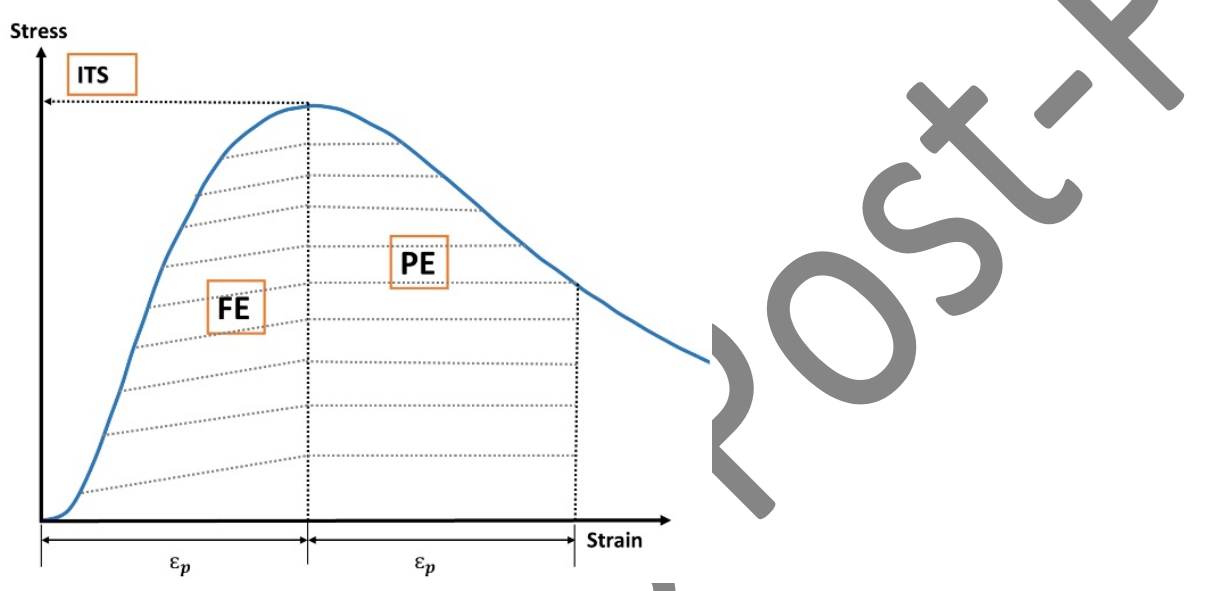

Fig.3. Scheme of toughness calculation.

On the other hand, moisture sensitivity was evaluated based on the indirect tensile strength ratio (ITSR). The ITSR is the ratio of the wet ITS to the dry ITS and is expressed in percentage as follows (see Eq. 2)

$$
\operatorname{ITSR}(\%)=\frac{I T S_{w e t}}{I T S_{d r y}} * 100
$$

Where $a$ and $A$ are the cross sections of the standpipe and the specimen in $\mathrm{mm}^{2}$ respectively; $L$ is the height of the specimen in $\mathrm{mm}$ and $t$ is the time required for the water to fall from an initial height of $300 \mathrm{~mm}$ above the sample $\left(h_{1}\right)$ to a height of $100 \mathrm{~mm}$ above the sample $\left(h_{2}\right)$. 
Author's post print: Carlos .J. Slebi-Acevedo Pedro. Lastra-González, Irunne. Indacoechea-Vega, Daniel. Castro-Fresno, Laboratory assessment of porous asphalt mixtures reinforced with synthetic fibers, Constr. Build. Mater. 234 (2020). doi:10.1016/j.conbuildmat.2019.117224.

\subsection{Statistical analysis}

Fourteen specimens of each PA mix design were performed with a total of 112 manufactured samples including the reference PA mixtures. The variability and uncertainty of the results in the experimental tests were statistically analysed. The test replicates of each mixture design can be seen in the experimental tested plan (see Table 6). Minitab software was used to support the analysis of the results. Anderson Darling Normality tests were carried out to determine if the data obtained followed a normal or non - normal data distribution._In addition, homogeneity of variance was checked through Levene test. Parametric statistical tests were used if the data followed a normal distribution and presented homogeneity of variance; otherwise, non parametric tests were used. The confidence interval considered was 95\%. Table 7 shows the statistical tests used to compare the data obtained from each mix design.

Table 7. Statistical tests to analyze the obtained data.

\begin{tabular}{lll} 
Data & Parametric tests & Non-parametric tests \\
\hline 2 groups & 2 samples t - test & Mann-Whitney Test \\
k groups & One way ANOVA & Kruskal-Wallis Test \\
\hline
\end{tabular}

\section{Results and Discussion}

Before carrying out the design of the PA mixtures, some previous tests were performed in the reference mixture to determine the optimal asphalt content based on the air void content, indirect tensile strength and Cantabro test results. According to the results, the bitumen content was fixed at $4.3 \%$ by weight of mixture. A binder drainage test was also carried out on the reference mixtures following the European standard procedure EN $12697-18$. According to the results, no binder drain-down was detected in any case. In order to isolate the reinforcement effect of the fiber on the experimental PA mixtures, the same binder content as for the reference mixture was used. Additionally, the influence of the filler content in the performance of the fiber reinforced PA mixture was considered by using two different filler concentrations.

\subsection{Permeability and volumetric properties}

The results concerning the volumetric properties and the permeability of the studied PA mixtures are summarized in Fig. 4 and Fig. 5, respectively. According to the results, the addition of the fiber did affect both the permeability and volumetric properties. It may be expected that the reduction of the total voids in the mixture implies a reduction of the permeability and the interconnected voids. In this case, the interconnected voids were positively correlated with the permeability values with a correlation coefficient of 0.88 , indicating a direct relationship between these two variables. Similarly, a positive relationship between the total air voids and the permeability was found with a correlation coefficient of 0.29 . Although in both cases a relation between the variables is observed, it can be concluded that the interconnected voids could be considered a better parameter to relate to permeability.

The results obtained before were statistically analysed. All the air void results followed a normal distribution and therefore a one way Anova Test was performed to determine if statistical differences among the results existed. Indeed, significant differences were observed between the reference mixture (RA) and the fiber reinforced mixtures with the same percentage of filler $\left(p_{\text {value }}=0.000\right)$. However, not statistical differences were reported among the results of the fiber reinforced mixtures $\left(p_{v a l u e}=0.198\right)$. Thus, although the addition of fibers significantly decreases the air voids with respect to the reference mixture, no differences among the air void content 
Author's post print: Carlos .J. Slebi-Acevedo Pedro. Lastra-González, Irunne. Indacoechea-Vega, Daniel. Castro-Fresno, Laboratory assessment of porous asphalt mixtures reinforced with synthetic fibers, Constr. Build. Mater. 234 (2020). doi:10.1016/j.conbuildmat.2019.117224.

of the different type of fibers were observed. Regarding to the interconnected voids and bulk density, the same phenomena occurred and no significant differences were found between the effect of the different fiber type $\left(p_{\text {value }}=0.397\right)$. On the other hand, the filler content has proved to be a relevant factor that affects the air void content in PA mixtures. In this sense, the close voids of RA and RB were found to be significantly different $\left(p_{\text {value }}=0.016\right)$. However, no significant differences were observed in the case of the fiber reinforced PA mixes independently of the filler content (pvalue=0.244). It can be concluded that in terms of the volumetric properties, the type and the length of the fiber are not determining. This is likely due to the low fiber content that is added to the mixture. Probably a higher amount could have a more relevant impact. Concerning the permeability results, the least permeable PA mixture was RB with $59.6 \%$ less permeability than RA mixture $\left(p_{\text {value }}=0.014\right)$. This phenomenon is likely due to the increased of close voids in RB (see Fig. 4) caused by the reduction of the filler content. On the other hand, focusing on the mixtures with higher filler content (i.e. Nomenclature A), PAN 4-A showed the lowest decrease in permeability, $14.7 \%$ reduction comparing to the reference (RA). It is likely that the longer the fiber length, the higher the negative impact on the permeability.

However, no significant differences were found within the fiber reinforced PA mixtures in terms of permeability. This is probably due, as suggested before, to the low fiber content $\left(p_{\text {value }}=0.498\right)$. Focusing on the mixtures with low filler content, the addition of fibers seems to increase the permeability of the PA mixture (Fig.4). According to the statistical analysis, this effect is significant and the mixture that presented the highest improvement comparing to the reference mixture $(\mathrm{RB})$ was the $\mathrm{PO} / \mathrm{A}-\mathrm{B}$ design $\left(p_{\text {value }}=0.050\right)$. The observed phenomenon could be due to the fact that by decreasing the filler/binder ratio, the fibers can absorb a higher amount of the light components of the bitumen. Similarly, focusing again on the PA mixes with the lower filler content, the addition of fibers appears to increase the interconnected voids leading to a higher permeability. In general terms, although slightly changes of permeability were found, the minimum recommended value in ASTM D7064-04 [16,36] was fulfilled $(1.2$ $\mathrm{mm} / \mathrm{s})$.

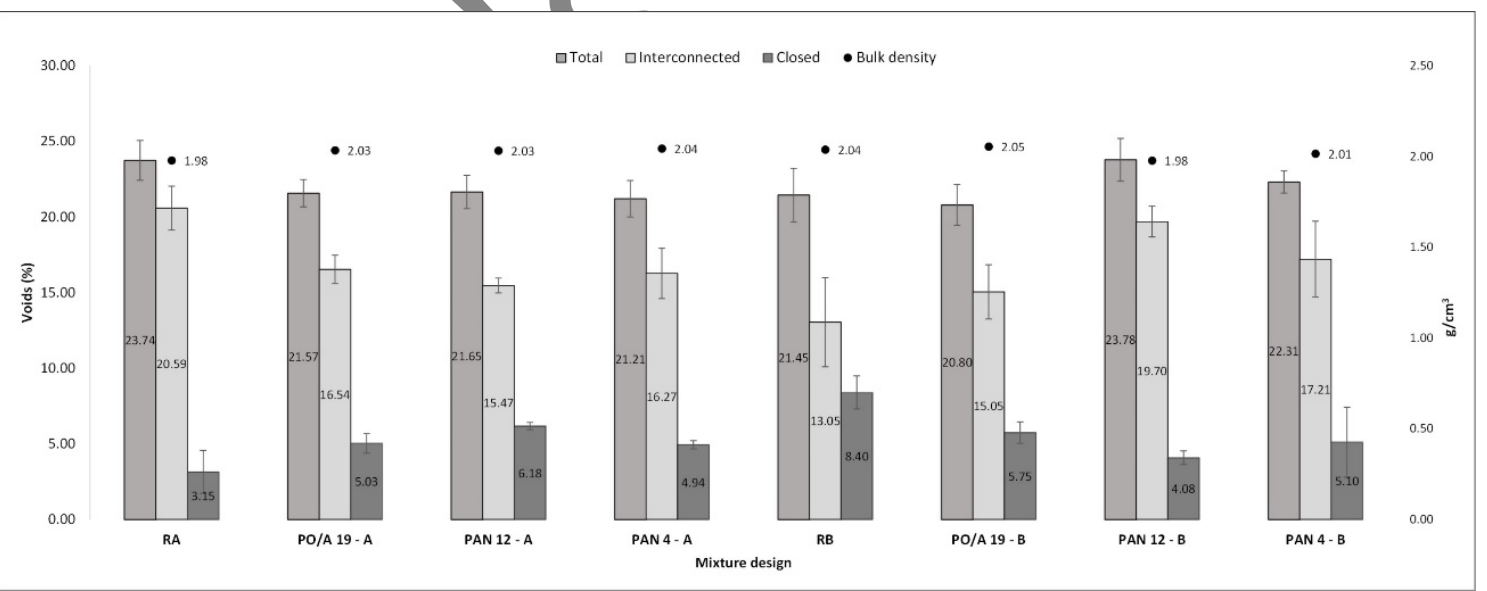

Fig.4. Volumetric properties of the PA mixture designs. The standard deviation from the mean is indicated by an error bar. 
Author's post print: Carlos .J. Slebi-Acevedo Pedro. Lastra-González, Irunne. Indacoechea-Vega, Daniel. Castro-Fresno, Laboratory assessment of porous asphalt mixtures reinforced with synthetic fibers, Constr. Build. Mater. 234 (2020).

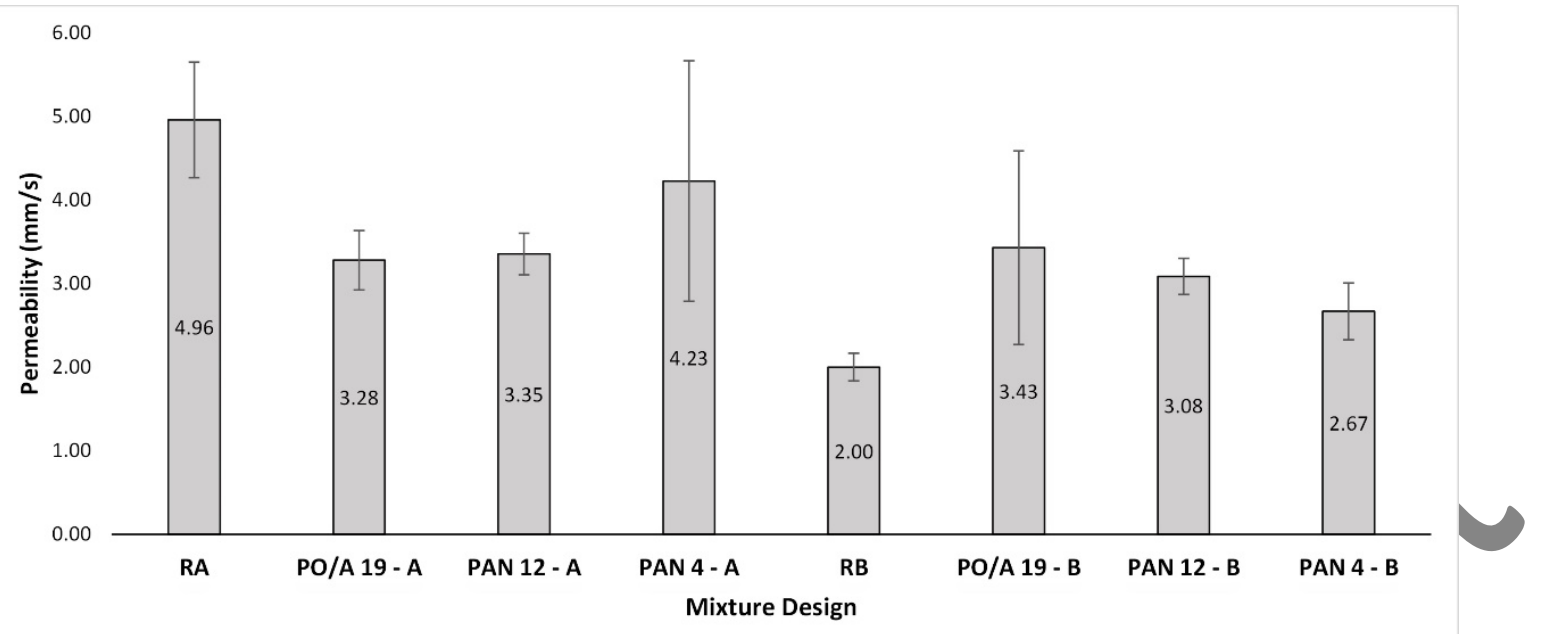

Fig. 5 Mean permeability values of PA mixture designs. The standard deviation from the mean is indicated by an error bar.

\subsection{Particle loss (Cantabro test)}

The results concerning the particle loss in dry conditions are shown in Fig. 6. According to the results, the use of fibers in the PA mixture positively affected its particle loss resistance. Specifically, the samples PO/A 19-A and PAN 4-A showed particle loss improvements of $33.7 \%$ and $15 \%$, respectively, respect the reference mixture RA. In addition, considering data dispersion, the differences among the reference mixture and the fiber reinforced mixture with PO/A were found to be statistically significant $\left(p_{\text {value }}=0.047\right)$. According to results, the higher impact provided by the polyolefin plus aramid fibers could be explained by the higher elastic modulus and tensile strength presented by the aramid fibers, which increase the reinforcement of the three-dimensional network formed in the asphalt mortar, leading to a lower susceptibility to particle losses. In the same way, similar improvements were reported in PA mixtures when crumb rubber was added [37]. On the other hand, it is worth mentioning that polyolefin fibers were fully dissolved due to the temperature of the mixing process. In this sense, Hejazi et al. [38] reported that slightly dissolved fibers provided a better bond strength with the bitumen within the hot mix asphalt. A more recent study indicated that an increase in the kinematic viscosity of the bitumen reduces the particle loss in the Cantabro test [39]. Regarding the impact of the filler content, no statistical differences were observed in the resistance to particle loss of RA and RB PA mixtures ( $\left.p_{\text {value }}=0.554\right)$. However, the addition of PO/A fibers to the PA mixtures with low filler content showed a higher increase in the particle loss resistance, observing a rise of $40-41 \%$ comparing to the reference mixtures being these results statistically different $\left(p_{\text {value }}=0.017\right)$. Furthermore, PAN fibers provided similar results to those provided by PO/A fibers. Specifically, PAN 12-B and PAN 4-B improved the resistance to particle loss by $31.7 \%$ and $22.3 \%$, respectively, in relation to the reference mixture (RB). Despite this, only the addition of the $12 \mathrm{~mm}$ PAN fibers turned out to be statistically significant $\left(p_{\text {value }}=0.050\right)$. As mentioned before, when the filler/binder ratio is reduced, there is a free amount of bitumen that can be absorbed by the fibers leading to a reinforcement of the three dimensional fiber-mortar networking matrix.

The results obtained in the Cantabro test carried out in wet conditions did not turn out as promising. Actually, reference mixture RA and fiber reinforced mixture PO/A 19-A presented the best results with a particle loss of 18.2 and 18.0, respectively. However, the differences among the results proved not to be statistically significant $\left(p_{\text {value }}=0.949\right)$. Overall, the addition of fibers 
Author's post print: Carlos .J. Slebi-Acevedo Pedro. Lastra-González, Irunne. Indacoechea-Vega, Daniel. Castro-Fresno, Laboratory assessment of porous asphalt mixtures reinforced with synthetic fibers, Constr. Build. Mater. 234 (2020). doi:10.1016/j.conbuildmat.2019.117224.

did not provide significant improvements in the mixture in wet conditions. This could indicate that these fibers are sensitive to water absorption. Focusing on the asphalt mixes with lower filler content, the initial hypothesis was that less filler content would increase the coating of the fibers by the bitumen and, therefore, increase the resistance to ravelling in wet conditions. However, similar results were obtained and no significant differences were found. As suggested by other researchers, lower filler contents decrease the viscosity and the amount of bituminous mastic that coats the aggregate particles leading to low thickness asphalt binder films on said particles. This will likely increase the susceptibility to moisture damage and decrease the resistance to the particle loss $[16,28]$. Thereby, these results suggest that the incorporation of fibers probably requires the addition of higher amounts of bitumen to completely coat the fibers and to prevent their exposition to the weather conditions.

口Dry conditions aWet Conditions

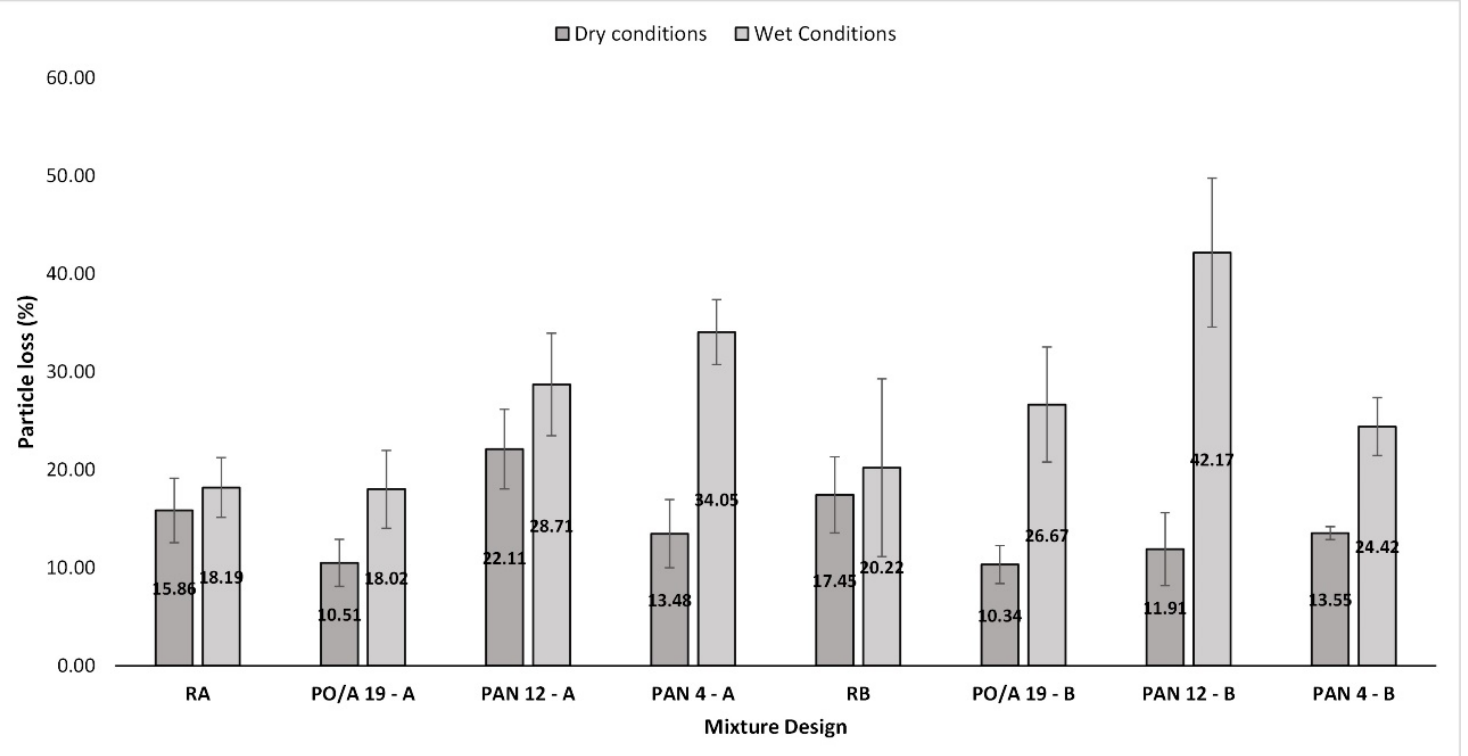

320

Fig. 6. Mean values of the Cantabro loss particle test in dry and wet conditions. The standard deviation from the mean is indicated by an error bar.

\subsection{Indirect tensile strength and moisture sensitivity}

The indirect tensile strength results in dry conditions are shown in Fig. 7. Based on these results, the increase of the ITS due to the addition of the different fibers is clearly observed. It should be noted that the length of the fiber has also an influence in the ITS, obtaining the highest improvements when long fibers are used. Thus, considering the mixtures with higher filler/binder ratio, the addition of PO/A fiber $(19 \mathrm{~mm})$ increases the indirect tensile strength in $22 \%$ as compared to the reference mixture $(\mathrm{RA})$, being this difference significant $\left(p_{\text {value }}=0.019\right)$. However, in the case of the mixtures with low filler content, $13.5 \%$ improvement achieved by the PO/A fiber has turned out to be insignificant $\left(p_{\text {value }}=0.060\right)$, although close to the limit of 0.05 with the $95 \%$ confidence interval. On the other hand, neither $12 \mathrm{~mm}$ nor $4 \mathrm{~mm}$ PAN fibers showed significant increases in the ITS values with $p_{\text {values }}$ of 0.156 and 0.530 , respectively. Moreover, the filler content was found to play an important role in the ITS of the asphalt mixtures. When the filler content is reduced, improvements of $20 \%, 11.7 \%$ and $7.01 \%$ were achieved in the reference mixture $\left(p_{\text {value }}=0.020\right)$, the $\mathrm{PO} / \mathrm{A}$ fiber reinforced mixture $\left(p_{\text {value }}=0.136\right)$ and the $12 \mathrm{~mm}$ PAN fiber reinforced mixture $\left(p_{\text {value }}=0.450\right)$, respectively. Nevertheless, only the result obtained in the reference mixtures is significantly different. 
Author's post print: Carlos .J. Slebi-Acevedo Pedro. Lastra-González, Irunne. Indacoechea-Vega, Daniel. Castro-Fresno, Laboratory assessment of porous asphalt mixtures reinforced with synthetic fibers, Constr. Build. Mater. 234 (2020). doi:10.1016/j.conbuildmat.2019.117224.

Concerning the ITS results in wet conditions (Fig. 7), the highest strength was also obtained when $\mathrm{PO} / \mathrm{A}$ fibers were added to the PA mixture, with an increase of $9.4 \%$ comparing to the reference mixture (RA). This is the only result significantly different $\left(p_{v a l u e}=0.050\right)$. The other fiber reinforced mixtures did not show any significant improvement. Based on these results, it can be concluded that the addition of fibers to the PA mixture improves only the ITS in dry conditions. In this sense, the ITSR values confirm the aforementioned conclusions (see Fig. 7). According to the results, RB mixture showed the highest ITSR value (86\%). However, it should be noted that the main reason for the observed reduction in ITSR when the fiber is added is caused by the increase of the ITS in dry conditions.

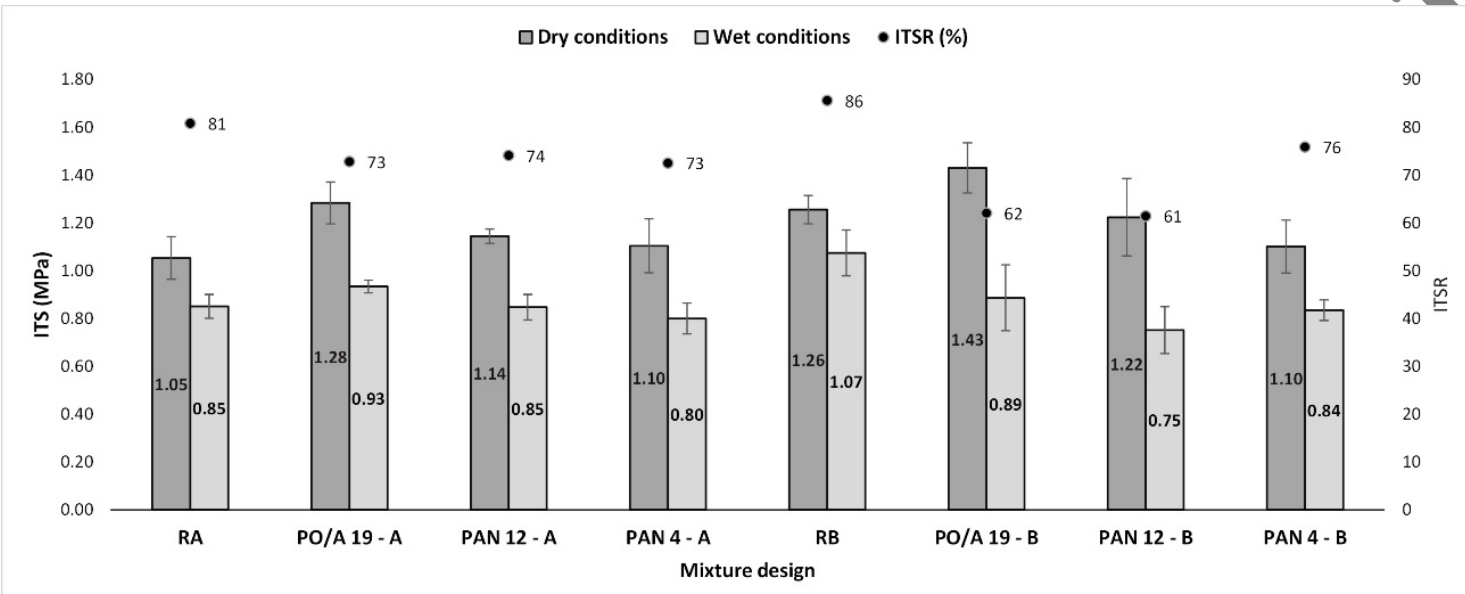

Fig. 7. Mean values of the Indirect Tensile Test (ITT). The standard deviation from the mean is indicated by an error bar.

\subsection{Toughness and Cracking resistance}

The Indirect Tensile Test (ITT) is considered by many researchers as the most adequate test to measure toughness given its simplicity, because not specialized instrumentation is required and because less than 1 minute is needed to perform it [40]. In this research, typical indirect tensile stress-strain curves were recorded in dry and wet conditions as shown in Fig. 8a and 8b, respectively. With a total of 48 specimens tested, the fracture energy (FE), post cracking energy (PE) and toughness mean values (series of three samples) are shown in Fig. 9 and 10 also in dry and wet conditions, respectively. Regarding the failure occurred, it was observed that the fracture tookplace in the mortar zone (cohesion failure) and in the zones closer to mortar-coarse aggregate interface. Sjmilar than reference mixture, changes in the breaking process were not noticed with the inclusion of fibers.

According to the results, in dry conditions, a slight increase of the initial stiffness is observed when adding fibers (Fig. 8a). Consequently, fracture energy is also increased providing the mixture with a more ductile behaviour. In this sense, the PAN 4-A mixture presented the major fracture energy with an increase of $46 \%$ comparing to the reference mixture RA ( $p_{\text {value }}=0.009$ ). Similarly, this mixture also reported the highest PE and toughness with increases of $23.5 \%$ and $32.1 \%$, respectively, compared to the reference mixture RA, being only the increase in toughness statistically significant $\left(p_{\text {value }}=0.024\right)$. This is likely due to the fact that short fibers are completely embedded in the asphalt mortar of the PA mixture, forming a three dimensional network in the mortar matrix and increasing the cohesive forces within the mortar [41]. Focusing on the samples with a lower filler content (B), the FE is slightly increased when PO/A fibers are added compared to the reference mixture (RB). In addition, it is interesting to note that, in dry conditions, the mixtures reinforced with PAN fibers (both 12 and $4 \mathrm{~mm}$ ) presented similar FE for both low and high filler content and although the PO/A19-A mixes presented $40 \%$ 
Author's post print: Carlos .J. Slebi-Acevedo Pedro. Lastra-González, Irunne. Indacoechea-Vega, Daniel. Castro-Fresno, Laboratory assessment of porous asphalt mixtures reinforced with synthetic fibers, Constr. Build. Mater. 234 (2020). doi:10.1016/j.conbuildmat.2019.117224.

higher FE than PO/A19-B mixes, the result turned out to be not statistically significant $\left(p_{\text {value }}=0.116\right)$. Therefore, changes in the filler content seem not to significantly affect the fracture energy of the PA mixtures. Similarly, slight increases in the post-cracking energy are generally observed in Fig. 9 when using fibers. It should be noted that an increase in the postcracking energy means a delay in the crack propagation when the pavement structure is subjected to traffic loads. Based on the results, PO/A fibers seem to achieve the greatest improvement in the post cracking energy. However, although PAN fibers reported improvements in relation of the reference mixture RA, lower PE results were obtained comparing to RB mixture.

Finally, when analysing the results obtained in the ITT test in wet conditions, no significant improvements are observed when fibers are added to the PA mixture (Fig. 10). This is probably due to a potential negative effect of water on the fiber reinforced PA mixtures tested. In this sense, Chen and Xu [42] measured the water absorption of different type of fibers, reporting an absorption of $11 \%$ in the case of PAN fibers. According to this, the fibers are also expected to contribute to prevent bitumen drainage so the use of a higher bitumencontent in these mixtures is not only possible but also highly recommended to avoid the negative water affection.

(a)

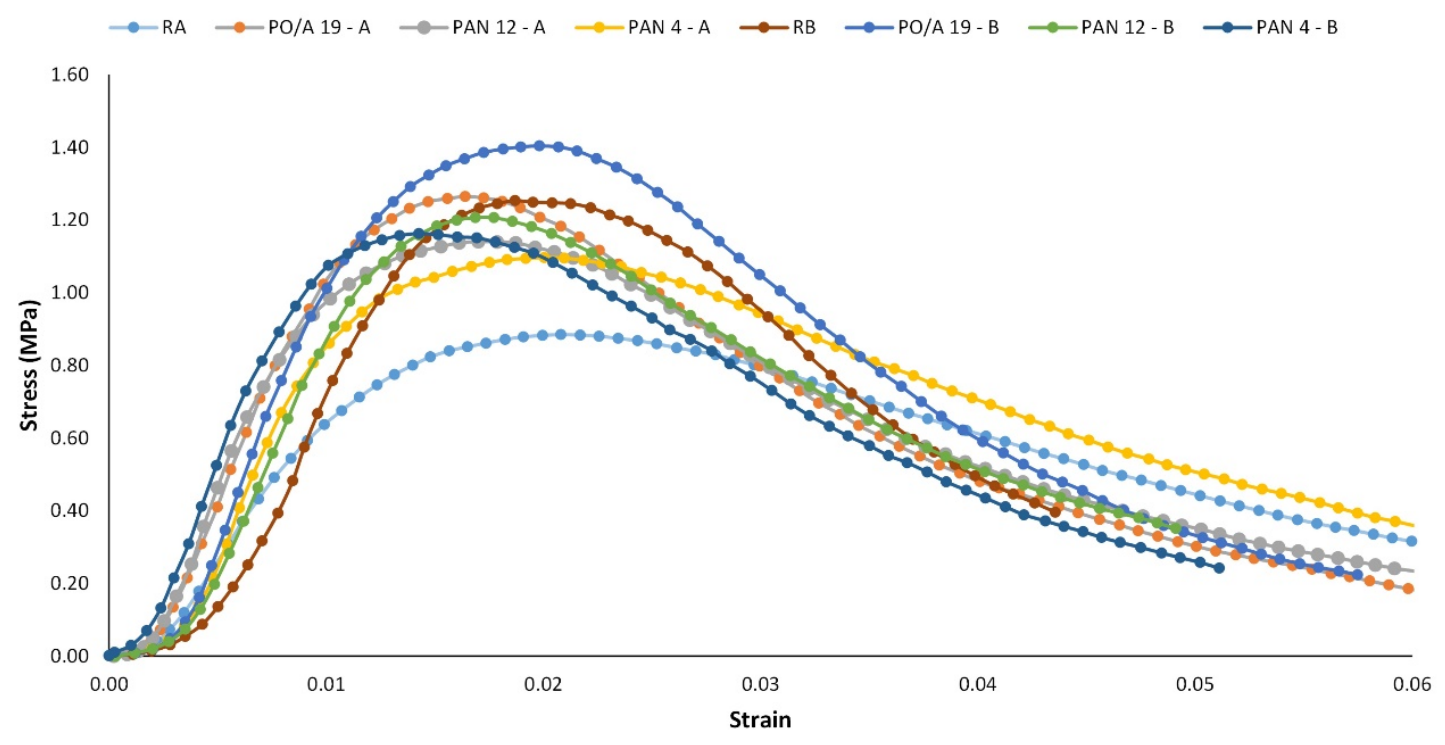


Author's post print: Carlos .J. Slebi-Acevedo Pedro. Lastra-González, Irunne. Indacoechea-Vega, Daniel. Castro-Fresno, Laboratory assessment of porous asphalt mixtures reinforced with synthetic fibers, Constr. Build. Mater. 234 (2020). doi:10.1016/j.conbuildmat.2019.117224.

(b)

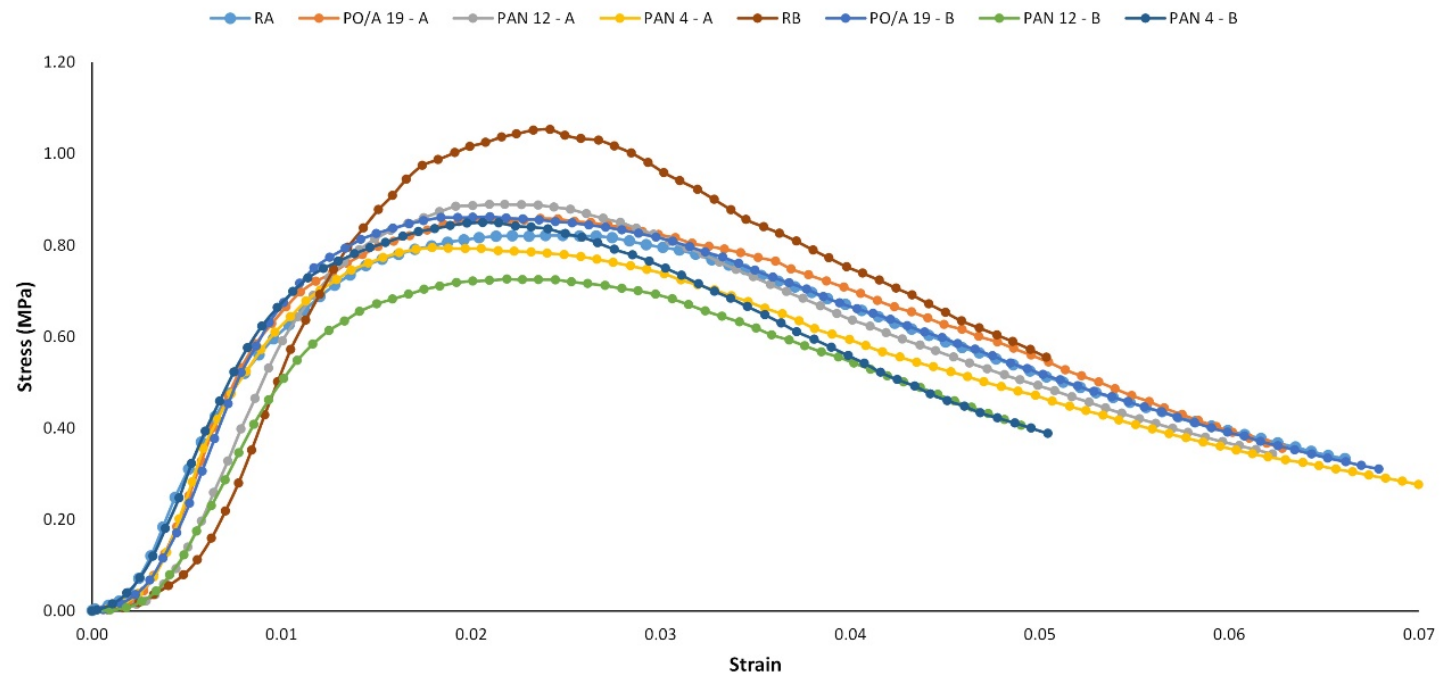

Fig. 8. Indirect Tensile Stress-Strain curves of PA mixtures: (a) Dry conditions; (b) Wet conditions.

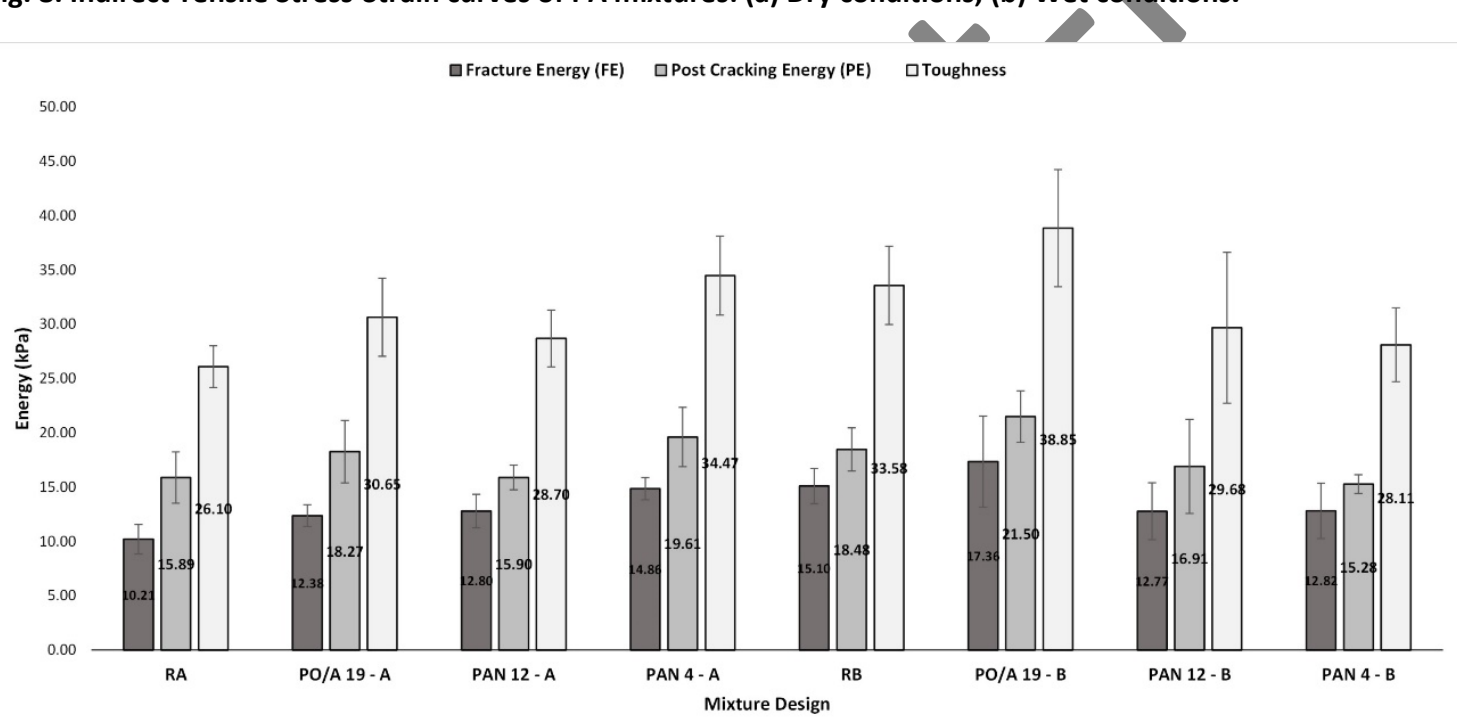

Fig. 9. Mean values of the fracture energy, post cracking energy and toughness in dry conditions. The standard deviation from the mean is indicated by an error bar.

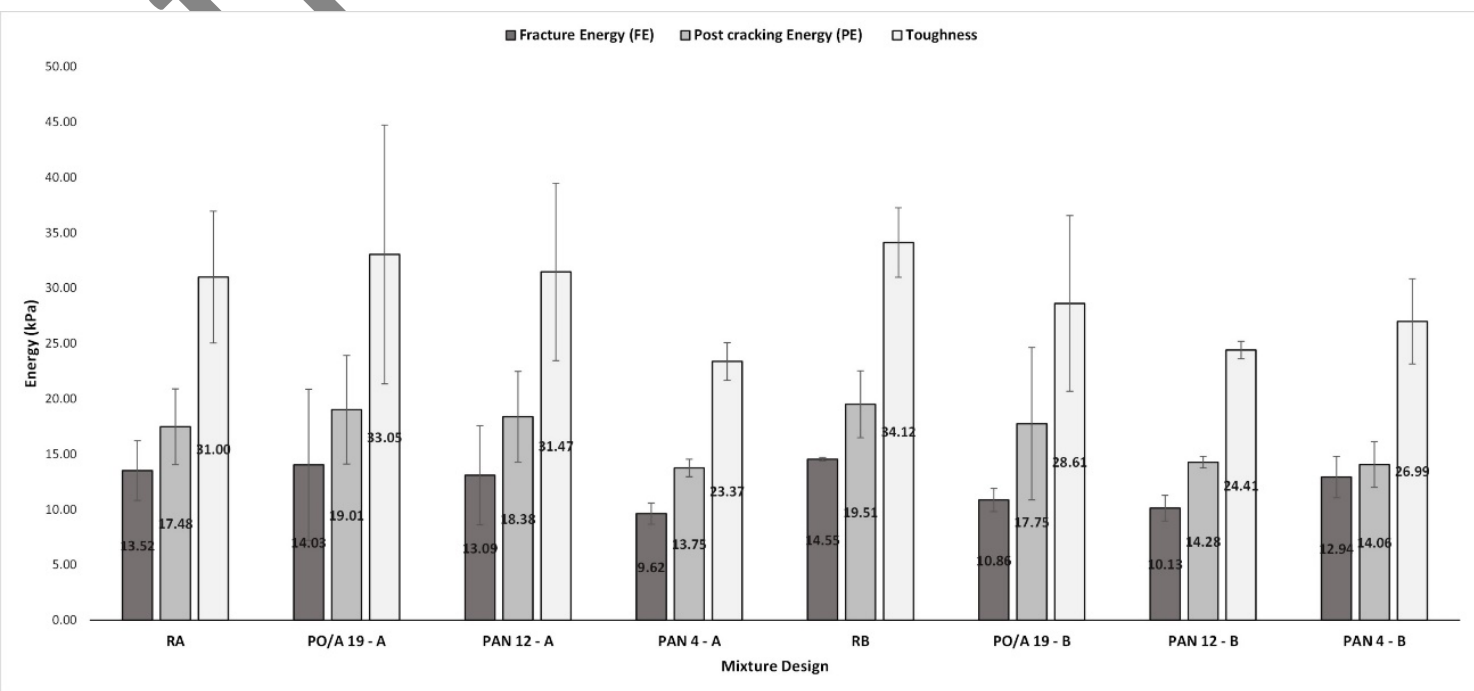


Author's post print: Carlos .J. Slebi-Acevedo Pedro. Lastra-González, Irunne. Indacoechea-Vega, Daniel. Castro-Fresno, Laboratory assessment of porous asphalt mixtures reinforced with synthetic fibers, Constr. Build. Mater. 234 (2020). doi:10.1016/j.conbuildmat.2019.117224.

Fig. 10. Mean values of the fracture energy, post cracking energy and toughness in wet conditions. The standard deviation from the mean is indicated by an error bar.

\section{Conclusions}

A laboratory assessment was performed to study the effect on the mechanical and functional performance of using synthetic fibers in porous asphalt mixtures. Specifically, a blend of polyolefin-aramid fibers and polyacrylonitrile were evaluated in this work. It should be noted that the same bitumen content was used in all the specimens in order to isolate the mechanical improvement provided by the fibers without considering their potential anti-drainage capacity. On the other hand, the impact of the filler/bitumen ratio on the results was analysed. Taking this into account, a set of PA mixtures were designed, manufactured and tested. Based on the results obtained, the following conclusions are presented.

- The use of the fibers in the PA mixture slightly reduces the total air void content when comparing to the reference mixtures. In any case, the minimum air void content established by the Spanish specifications was accomplished (20\%).

- The addition of fibers to the PA mixture improved their mechanical performance in dry conditions. However, no significant improvements were observed in wet conditions. It is believed that to fully incorporate the fibers in the binder-aggregate matrix, a higher amount of bitumen is needed, thus also taking advantage of the anti-drainage capacity of the fibers. Otherwise, the use of the fibers in dense graded mixtures (AC or SMA) is recommended.

- Concerning the particle loss test, the addition of PO/A fibers to the PA mixture influenced positively the resistance to particle loss, reducing the rate of weight loss in the Cantabro test. On the other hand, the filler content seemed not to affect significantly the particle loss results.

- The addition of fibers to the PA mixture resulted in an increase of the indirect tensile strength (ITS) of the dry conditioned specimens. On the other hand, similar or lower strengths than the reference were found when wet conditioned specimens of fiber reinforced $P A$ mixtures were tested.

- The addition of PAN4-A and PO/A19-B type of fibers to the PA mixture showed the highest improvements in terms of the fracture energy, post cracking energy and toughness of the dry conditioned specimens comparing to the reference mixtures RA and $\mathrm{RB}$ respectively. No improvements were observed concerning toughness for the fiber reinforced wet conditioned specimens.

- Overall, considering the obtained results, the highest mechanical and functional performance of the PA mixtures were provided by the addition of the PO/A fibers.

- Further investigations are needed in order to evaluate the performance of these type of fibers in PA mixtures considering other variables such as fiber concentration, bitumen content, and bitumen type or particle size distribution. Life cycle cost analysis of the reinforced porous asphalt mixtures with fibers is also recommended to be another research topic.

\section{Acknowledgements}

This work was possible thanks to the research project entitled "Fostering the implementation of fibre-reinforced asphalt mixtures by ensuring its safe, optimized and cost-efficient use" and financed by the CEDR Transnational Road Research Programme - call 2017 under the contract 
Author's post print: Carlos .J. Slebi-Acevedo Pedro. Lastra-González, Irunne. Indacoechea-Vega, Daniel. Castro-Fresno, Laboratory assessment of porous asphalt mixtures reinforced with synthetic fibers, Constr. Build. Mater. 234 (2020). doi:10.1016/j.conbuildmat.2019.117224.

$444 \quad$ N. 867481. The authors wish to express their gratitude to FORTA-FI ${ }^{\circledR}$ and Lambda Furtherance

B. $V$ for provide the fibers to this research project.

\section{References}

[1] M.E. Barrett, P. Kearfott, J.F. Malina, Stormwater Quality Benefits of a Porous Friction Course and Its Effect on Pollutant Removal by Roadside Shoulders, Water Environ. Res. 78 (2006) 2177-2185. doi:10.2175/106143005X82217.

[2] M.L. Afonso, M. Dinis-Almeida, C.S. Fael, Study of the porous asphalt performance with cellulosic fibres, Constr. Build. Mater. 135 (2017) 104-111. doi:10.1016/j.conbuildmat.2016.12.222.

[3] V.S. Punith, A. Veeraragavan, Characterization of OGFC Mixtures Containing Reclaimed Polyethylene Fibers, J. Mater. Civ. Eng. 23 (2011) 335-341. doi:10.1061/(ASCE)MT.1943-5533.0000162.

[4] Y. Decoene, Contribution of cellulose fibers to the performance of porous asphalts, Trans. Res. Rec.,. 1265 (1990) 82-86.

[5] R. Clifford, S. Dillon, G. Walsh, I. Jamieson, Design and performance of porous asphalt mixes in Ireland, Natl. Roads Authority, Dublin. RC.376 (1996).

[6] H. Rondón, F. Reyes, Pavimentos, materiales construcción y diseño, Ecoe-edici, Bogotá Colombia, n.d.

[7] J.F. Adam, A.C. Brooker, S.H. Carpenter, A.D. John, G. Huber, D.C. Jackson, P.E. Krugler, D. Lee, R.S. Mcdaniel, D.B. Mellott, J.S. Moulthrop, S. Shuler, M. Stroup-gardiner, K.K. Tam, OPEN-GRADED FRICTION COURSE: STATE OF THE PRACTICE. Transportation Research Circular E-C005, Transp. Res. Circ. E-C005. (1998) 20.

[8] T.N. Mansour, B.J. Putman, Influence of aggregate gradation on the performance properties of porous asphalt mixtures, J. Mater. Civ. Eng. 25 (2013) 281-288.

[9] H.A. Smith, Performance Characteristics of Open-Graded Friction Courses. In NCHRP Synthesis of Highway Practice 180, TRB, Natl. Res. Counc. Washington, D.C. (1992).

[10] A. Massahi, H. Ali, F. Koohifar, M. Baqersad, Investigation of pavement raveling performance using smartphone, Int. J. Pavement Res. Technol. 11 (2018) 553-563. doi:10.1016/j.ijprt,2017.11.007.

[11] L. Mo, M. Huurman, S. Wu, A.A.A. Molenaar, Ravelling investigation of porous asphalt concrete based on fatigue characteristics of bitumen-stone adhesion and mortar, Mater.Des. 30 (2009) 170-179. doi:10.1016/j.matdes.2008.04.031.

[12] F. Moreno-navarro, G. García-travé, M.D.E.L.C. Rubio-gámez, M.J. Martinez-echevarria, comparison of two laboratory test methods ANALYSIS OF THE MOISTURE SUSCEPTIBILITY OF HOT BITUMINOUS MIXES BASED ON THE COMPARISON OF TWO LABORATORY TEST METHODS, (2014). doi:10.15446/dyna.v81n183.30893.

[13] L.D. Poulikakos, M.N. Partl, Asphalt Through Various Mechanical Tests, (2004).

[14] K.K. S. Mathavan, M. M. Rahman, , M. Stonecliffe-Jones, Pavement Raveling Detection and Measurement from Synchronized Intensity and Range Images, J. Transp. Res. Board. 2457 (n.d.) 3-11. doi:doi.org/10.3141/2457-01.

[15] C.J. Slebi-acevedo, P. Lastra-gonzález, P. Pascual-muñoz, D. Castro-fresno, Mechanical performance of fibers in hot mix asphalt : A review, Constr. Build. Mater. 200 (2019) 
Author's post print: Carlos .J. Slebi-Acevedo Pedro. Lastra-González, Irunne. Indacoechea-Vega, Daniel. Castro-Fresno, Laboratory assessment of porous asphalt mixtures reinforced with synthetic fibers, Constr. Build. Mater. 234 (2020). doi:10.1016/j.conbuildmat.2019.117224. 756-769. doi:10.1016/j.conbuildmat.2018.12.171.

[16] V.C. Andrés-Valeri, J. Rodriguez-Torres, M.A. Calzada-Perez, J. Rodriguez-Hernandez, Exploratory study of porous asphalt mixtures with additions of reclaimed tetra pak material, Constr. Build. Mater. 160 (2018) 233-239. doi:10.1016/j.conbuildmat.2017.11.067.

[17] A.E. Alvarez, A.E. Martin, C. Estakhri, A review of mix design and evaluation research for permeable friction course mixtures, Constr. Build. Mater. 25 (2011) 1159-1166. doi:10.1016/j.conbuildmat.2010.09.038.

[18] S.J. Lee, J.P. Rust, H. Hamouda, R. Kim, R.H. Borden, Fatigue Cracking Resistance of Fiber-Reinforced Asphalt Concrete, Text. Res. J. 75 (2005) 123-128. doi:10.1177/004051750507500206.

[19] L.M.G. Klinsky, K.E. Kaloush, V.C. Faria, V.S.S. Bardini, Performance characteristics of fiber modified hot mix asphalt, Constr. Build. Mater. 176 (2018) 747-752. doi:10.1016/j.conbuildmat.2018.04.221.

[20] Q. Xu, H. Chen, J.A. Prozzi, Performance of fiber reinforced asphalt concrete under environmental temperature and water effects, Constr. Build. Mater. 24 (2010) 20032010. doi:10.1016/j.conbuildmat.2010.03.012.

[21] A. Chowdhury, J.W. Button, A. Bhasin, Fibers from recycled tire as reinforcement in hot mix asphalt, 2006.

[22] Y.-C.C.\& A.-Q.N. Xiang Ma, Qiang Li, Performance of porous asphalt mixture with various additives, Int. J. Pavement Eng. 19 (2018) 355-361. doi:10.1080/10298436.2016.1175560.

[23] D. Movilla-quesada, A.C. Raposeiras, O. Muñoz, D. Castro-fresno, Reduction in the use of mineral aggregate by recycling cellulose ashes to decrease the aging of hot asphalt mixtures, Constr. Build.Mater. 143(2017) 547-557. doi:10.1016/j.conbuildmat.2017.03.154.

[24] M. Ardanuy, J. Claramunt, R.D. Toledo Filho, Cellulosic fiber reinforced cement-based composites: A review of recent research, Constr. Build. Mater. 79 (2015) 115-128. doi:10.1016/j.conbuildmat.2015.01.035.

[25] L.Yan, B. Kasal, L. Huang, A review of recent research on the use of cellulosic fibres, their fibre fabric reinforced cementitious, geo-polymer and polymer composites in civil engineering, Compos. Part B Eng. 92 (2016) 94-132. doi:10.1016/j.compositesb.2016.02.002.

[26] PG-3, Pliego de prescripciones técnicas generales para obras de carreteras y puentes. PG-3, Pliego de prescripciones técnicas generales para obras de carreteras
Art. 542. Mezclas bituminosas tipo hormigón bituminoso., (2015) 514 p.

[27] M.R.M. Aliha, A. Razmi, A. Mansourian, The influence of natural and synthetic fibers on low temperature mixed mode I + II fracture behavior of warm mix asphalt (WMA) materials, Eng. Fract. Mech. 182 (2017) 322-336. doi:10.1016/j.engfracmech.2017.06.003.

[28] K.R. Lyons, B.J. Putman, Laboratory evaluation of stabilizing methods for porous asphalt mixtures, Constr. Build. Mater. 49 (2013) 772-780. doi:10.1016/j.conbuildmat.2013.08.076.

[29] S. Suresha, G. Varghese, A. Shankar, A comparative study on properties of porous 
Author's post print: Carlos .J. Slebi-Acevedo Pedro. Lastra-González, Irunne. Indacoechea-Vega, Daniel. Castro-Fresno, Laboratory assessment of porous asphalt mixtures reinforced with synthetic fibers, Constr. Build. Mater. 234 (2020). doi:10.1016/j.conbuildmat.2019.117224.

friction course mixes with neat bitumen and modified binders., Constr. Build Mater. 23 (2009) 1211-7.

[30] J. Miró, F. Pérez, Procedure for the evaluation of asphalt binders ageing in contact with aggregates and application of this procedure to analyze the influence of the aggregate type on binder ageing., Road Mater Pavement Des. 2 (2001) 97-110.

[31] M.A. Calzada-Perez, F.E. Perez-Jimenez, Desarrollo y normalización del ensayo de pérdida por desgaste aplicado a la caracterización, dosificación y control de mezclas bituminosas de granulometría abierta., Universidad de Cantabria, 1984.

[32] F.E.P. Jimenez, M.A.C. Perez, Analysis and evaluation of the performance of porous asphalt. The Spanish experience, ASTM Spec. Tech. Publ. First Int. Symp. Surf. Charact. State Coll. PA, USA. Code 13688 (1988) 512-527.

[33] P. Park, S. El-Tawil, S.-Y. Park, A.E. Naaman, Cracking resistance of fiber reinforced asphalt concrete at $-20^{\circ} \mathrm{C}$, Constr. Build. Mater. 81 (2015) 47-57. doi:10.1016/j.conbuildmat.2015.02.005.

[34] F. Jin, K. Gu, A. Abdollahzadeh, A. Al-Tabbaa, Effects of Different Reactive MgOs on the Hydration of MgO-Activated GGBS Paste, J. Mater. Civ. Eng. 27 (2013) 1239-1247. doi:10.1061/(ASCE)MT.

[35] A. Alvarez, A. Epps Martin, C. Estakhri, J. Button, C. Glover, S. Jung, Synthesis of current practice on the design, construction, and maintenance of porous friction courses., 2006.

[36] ASTM D7064-04, Standard practice for open-graded friction course (OGFC) mix design, n.d.

[37] C. Sangiorgi, S. Eskandarsefat, P. Tataranni, A. Simone, V. Vignali, C. Lantieri, G. Dondi, A complete laboratory assessment of crumbrubber porous asphalt, Constr. Build. Mater. 132 (2017) 500-507. doi:10.1016/j.conbuildmat.2016.12.016.

[38] S.M. Hejazi, M. Abtahi, M. Sheikhzadeh, D. Semnani, Using artificial neural network for the investigation of some fiber parameter performances in reinforced asphalt concrete (FRAC), Asph. Technol. Pavement Eng. (2008).

[39] X. Ma, Q. Li, Y. Cui, A. Ni, Performance of porous asphalt mixture with various additives, Int. J. Pavement Eng. (2016).

[40] F. Zhou, S. Im, L. Sun, T. Scullion, Development of an IDEAL cracking test for asphalt mix design and QC/QA, Asph. Paving Technol. Assoc. Asph. Paving Technol. Tech. Sess. 86 (2017) 549-577. doi:10.1080/14680629.2017.1389082.

[41] J.S. Chen, K.Y.I. Lin, Mechanism and behavior of bitumen strength reinforcement using fibers, J. Mater. Sci. 40 (2005) 87-95. doi:10.1007/s10853-005-5691-4.

[42] H. Chen, Q. Xu, Experimental study of fibers in stabilizing and reinforcing asphalt binder, Fuel. (2010). doi:10.1016/j.fuel.2009.08.020. 